Cadernos Walter Benjamin 25

\title{
WALTER BENJAMIN E O TÚMULO DOS VAGALUMES: NARRATIVA E EXPERIÊNCIA
}

Heraldo Aparecido Silva

Lara Brenda Lima de Oliveira

\begin{abstract}
RESUMO
O presente trabalho propõe uma análise da animação japonesa Túmulo dos vagalumes a partir das ideias do filósofo alemão Walter Benjamin. A animação é baseada em fatos reais e foi adaptada, dirigida e produzida por Isao Takahata, um dos criadores do Studio Ghibli que é responsável por relevantes produções da indústria do cinema japonês. Inicialmente, é apresentada uma breve sinopse da animação, juntamente com a descrição feita por Benjamin acerca dos temas narrativa e experiência. Em seguida, são estabelecidos nexos entre a animação e as ideias do filósofo alemão. A primeira análise que se faz é que o personagem central da trama descrita em Túmulo dos vagalumes se configura como um narrador benjaminiano, pois o mesmo traz consigo a importante tarefa de relatar a sua dramática experiência de vida. O enredo da animação revela uma trágica experiência que Seita e Setsuko, os protagonistas, desejam externar. Tal experiência configura, sob a forma de uma narrativa feita através de palavras e imagens, uma mensagem para o mundo: que suas histórias não sejam de fato esquecidas; pelo contrário, a lição de moral retirada dessa narrativa revela que é contando a história que se evitará que tragédias como essas não possam se repetir no futuro. Nota-se também que as experiências enfatizadas pelo filósofo mostram-se cada dia mais empobrecidas, algo que é constatado nas relações estabelecidas entre as pessoas com atitudes emblematicamente egoístas, retratadas em Túmulo dos Vagalumes. Portanto, os aspectos abordados por Benjamin dialogam com a referida animação, revelando uma miríade de possibilidades existentes na identificação de temas filosóficos na obra cinematográfica.
\end{abstract}

Palavras-chave: Experiência. Narrativa. Benjamin. Anime. Studio Ghibli.

\section{WALTER BENJAMIN AND THE TUMB OF VAGALUMES: NARRATIVE AND EXPERIENCE}

\begin{abstract}
The present work proposes an analysis of the Japanese animation Tomb of fireflies based on the ideas of the German philosopher Walter Benjamin. The animation is based on real events and was adapted, directed and produced by Isao Takahata, one of the creators of Studio Ghibli who is responsible for relevant

Doutor em Filosofia (UFSCAR). Docente do Programa de Pós-graduação em Filosofia (UFPI). Brasileiro. Residente em Teresina-PI. E-mail: heraldokf@yahoo.com.br

Graduanda em Pedagogia. Bolsista de Iniciação Científica PIBIC/CNPq (UFPI). Brasileira.
\end{abstract} Residente em Teresina-PI. E-mail: laralima18@hotmail.com 
productions in the Japanese film industry. Initially, a brief synopsis of the animation is presented, along with Benjamin's description of the themes of narrative and experience. Next, connections are made between animation and the ideas of the German philosopher. The first analysis that is done is that the central character of the plot described in Tomb of fireflies is configured as a Benjamin narrator, as he brings with him the important task of reporting his dramatic life experience. The animation plot reveals a tragic experience that Seita and Setsuko, the protagonists, want to share. Such an experience constitutes, in the form of a narrative made through words and images, a message to the world: that their stories are not in fact forgotten; on the contrary, the moral lesson from this narrative reveals that it is by telling the story that tragedies such as these cannot be repeated in the future. It is also noted that the experiences emphasized by the philosopher prove to be increasingly impoverished, something that is seen in the relationships established between people with emblematic selfish attitudes, as portrayed in Tomb of the Fireflies. Therefore, the aspects approached by Benjamin dialogue with that animation, revealing a myriad of possibilities that exist in the identification of philosophical themes in cinematographic work.

Keywords: Experience. Narrative. Benjamin. Anime. Studio Ghibli.

\section{Introdução}

Este presente trabalho visa compreender e estabelecer uma relação entre a animação japonesa Túmulo dos vagalumes e os aspectos referentes às noções de narrativa e experiência contidos nas obras $O$ narrador: Considerações sobre Nikolai Leskov e Experiência e Pobreza de Walter Benjamin. No decorrer do presente texto, outros aportes teóricos também serão mencionados.

Túmulo dos vagalumes (Hotaru no Haka) animação da década de 80 , produzida no Japão e posteriormente disponível para outros países inclusive uma versão legendada para o português. Marcou gerações pela forte mensagem que passou por intermédio do drama vivenciando durante o período conflitante de uma guerra, e pela forma como retratou esse cenário utilizando a figura de duas crianças. Ao retratar a guerra, não retratou em seu trabalho, imagens batalhas e soldados feridos ou mortos, tão somente exprimiu a tragédia resultante de interesses humanos em jogo. Onde se é possível revelar a verdadeira face humana, o que a guerra pode causar nas pessoas, os sentimentos de maldade e indiferença em frente a inocência de uma criança que 
não é capaz de ver o mal. A intenção é de chocar e comover o público com uma narrativa que não se encontra tão distante da nossa realidade.

Os dois personagens centrais representam nitidamente as vozes silenciadas pela guerra. O roteirista Isao Takahata irá repassar por intermédio desses, o sentimento desmoralizante da guerra, provocando uma sensibilidade sem sensacionalismos, buscando por meios de coisas simples retratar a história de um país de um povo e de uma tradição. São aspectos relevantes para a compreensão o contexto histórico, os aspectos geográficos assim como as mensagens subtendidas que proporcionam um olhar para além da guerra, que se volta para o personagem e a simplicidade de viver.

E é por meio de personagens cativantes de uma história repleta de emoção e ação, com um caráter moralizante que se buscará estabelecer uma relação com os clássicos escritos do filósofo alemão Walter Benjamin. Este que contribuiu com seu acervo de obras e conhecimentos que refletem muito mais nos dias atuais. A narrativa e o narrador e o sentido da experiência elementos tão importantes que serão estabelecidos em Túmulo dos vagalumes.

\section{Túmulo dos vagalumes}

O Studio Ghibli é responsável por grandes e reconhecidas produções da indústria de cinema japonês. Sediado em Koganei, Tóquio fundado em 1985 por Hayao Miyazaki, Isao Takahata, Toshio Suzuki e Yasuyoshi Tokuma. Artista e criador prolífico, com incursões também no universo dos mangás, Miyazaki detém de mais de 20 animações de longa-metragem, como também importantes premiações do cinema internacional. Duas produções de Miyazaki, $A$ viagem de Chihiro (2001) e O Castelo Animado (2004) ganharam, respectivamente, o Urso de Ouro do Festival de Berlim em 2002 e o Oscar de Melhor Longa-Metragem de Animação em 2006 (MOLINÉ, 2006). Inicialmente Hayao Miyazaki e Isao Takahata trabalharam juntos na produção do anime (Hidei Arupu no Shojo) em 1974, que ganhou bastante destaque na época. A União desses dois produtores deu início ao que conhecemos como o Studio Ghibli, que traduzido da língua nippon "Ghibli" significa "vento". O vento que segundo Miyazaki mudaria a história da animação japonesa (STUDIO GHIBLI, 2004).

Doutor em Filosofia (UFSCAR). Docente do Programa de Pós-graduação em Filosofia (UFPI). Brasileiro. Residente em Teresina-PI. E-mail: heraldokf@yahoo.com.br

Graduanda em Pedagogia. Bolsista de Iniciação Científica PIBIC/CNPq (UFPI). Brasileira. Residente em Teresina-PI. E-mail: laralima18@hotmail.com 
É importante notar que tanto Hayao Miyazaki quanto Isao Takahata tiveram experiências individuais de "[...] trabalhos com diferentes companhias de animação antes de formarem o seu próprio estúdio" (ODELL; LE BLANC, 2009, 78-79, tradução nossa). Nessa perspectiva, a origem do Studio Ghibli pode ser explicada pela necessidade de ambos os animadores de "[...] continuar seu trabalho sem comprometer sua visão artística, contando histórias do jeito que eles queriam contar" (ODELL; LE BLANC, 2009, 14, tradução nossa).

A primeira animação lançada foi Lapyuta: O castelo no céu (Tenku no Shiro Rapyuto) em 1986, tornou-se um sucesso de bilheteria e o ponta pé inicial para outras produções que iriam alavancar o reconhecimento do estúdio. Em 1988 são lançados duas animações simultaneamente, Meu vizinho Totoro (Tonari no Totoro) roteirizado por Hayao Miyazaki e O túmulo dos Vagalumes (Hotaro no Haka) de Isao Takahata, duas obras bem distintas visando alcançar públicos variados. Enquanto a animação $\mathrm{Meu}$ vizinho Totoro trazia um enredo de aventura e magia, atraindo um grande público infantil, Túmulo dos Vagalumes é ambientado no cenário da Segunda Guerra Mundial.

Entretanto, embora a animação O Túmulo dos Vagalumes seja ambientada no cenário nipônico do final da Segunda Guerra Mundial, é preciso elucidar que o mesmo não deve ser considerado, de forma precipitada, meramente como um filme de guerra. Essa interpretação mais cautelosa pode ser explicada nos seguintes termos:

\footnotetext{
Embora o bombardeio de Tokyo e as bombas nucleares lançadas sobre Nagasaki e Hiroshima sejam mais lembrados, a infinidade de outras cidades arrasadas é menos documentada. O Túmulo dos Vagalumes não é um filme de guerra no sentido tradicional, mas antes, um filme sobre as consequências da guerra e seus efeitos sobre os indivíduos, longe das manchetes da grandes batalhas e manobras do exército (ODELL; LE BLANC, 2009, 190-191, tradução nossa).
}

Túmulo dos Vagalumes (1988) é um longa-metragem com duração de 89 minutos, dirigido por Isao Takahata um dos fundadores do Studio Ghibli, conforme já mencionado. Takahata nasceu no ano de 1935 e iniciou sua produção no estúdio com as animações; Túmulo dos vagalumes, $A$ princesa Kaguya e Only yesterday; faleceu recentemente em 2018 deixando um legado 
de grandes obras (IMDB, 2018). Sua produção Hotaru no Haka trata-se de uma adaptação do relato semiautobiográfico Túmulo dos vagalumes, do cantor e romancista Akyuki Nosaka (1930-2015), baseado em fatos reais vivenciados durante sua infância no período da Segunda Guerra Mundial. Originalmente, Túmulo dos vagalumes, foi publicado como um conto no ano de 1967 e venceu o prêmio Naoki. Somente décadas mais tarde, o referido conto foi adaptado para outras mídias como o anime, em 1988; e o live action, em 2005 (ODELL; LE BLANC, 2009).

A animação Túmulo dos Vagalumes (1988) retrata a história de dois irmãos, Seita de 9 anos, irmão mais velho e responsável por sua irmã Setsuko de apenas 4 anos, habitantes da cidade de Kobe, pertencente à província de Hyogo. No ano de 1945 o Japão sofre ataques e a referida cidade é bombardeada por ataques aéreos de caças norte-americanos, o que provoca milhares de mortes e uma ampla destruição. A trama se desenvolve em torno da tentativa de sobrevivência por parte de duas crianças em um contexto de guerra. Com o pai militar longe de casa, lutando pelas tropas navais japonesa e a súbita perda da mãe num trágico ataque inimigo, Seita e Setsuko iniciam sua jornada de sofrimento e lutas.

Após perderem os pais muito cedo, Seita e Setsuko vão morar com uma tia, parente mais próximo da família. De início a relação entre eles aparentemente se estabelece normal, embora a tia seja uma senhora ambiciosa e indiferente. As crianças possuíam alguns bens materiais o que garantiu seu sustento na casa, já que são tratados mais como inquilinos do que como parentes, todavia essa relação não vai muito bem e logo surgem os conflitos. Constantemente insultados pela tia, que os vê como peso, as crianças acabam sofrendo abusos verbais e são obrigados a se virarem sozinhos. Não suportando toda humilhação, Seita toma a decisão de deixar a casa e ir morar junto com Setsuko em um local abandonado próximo a floresta.

O rumo de suas vidas mudará totalmente, e eles seguirão nessa tentativa de sobreviverem sem o apoio de ninguém e diante de um cenário de conflitos e desesperança. Diante disso Seita é levado a fazer de quase tudo para alimentar sua irmã e a si próprio, enfrentando os perigos dos ataques aéreos, as 
humilhações e agressões. Atitudes que põem em risco sua vida, mas que em um ato de desespero se tornam necessário para viver. O sofrimento se revela cruel, fome, doenças e solidão afligem os dois irmãos, e Setsuko por ser mais jovem e consequentemente mais frágil, se torna vítima perfeita. $E$ a vida se mostra sem rumo ou sem direção para duas crianças na tentativa de sobreviverem e resistirem a realidade cruel da guerra. E assim por desnutrição, mastigando um bolinho de terra, Setsuko assim como um vagalume deixa de brilhar, e a vida se torna uma desilusão. Após perder a irmã, Seita não vê motivos para continuar vivendo e torna-se outra vítima dos horrores provocado pela guerra.

\begin{abstract}
Túmulo dos vagalumes nos mostra um microcosmos dos efeitos da guerra e a maneira como esse conflito pode desumanizar as pessoas. Não é um filme sobre soldados [...] mas sobre civis que têm pouca compreensão sobre a natureza ou proposito da guerra. Mostra como o horror do conflito e a exposição à atrocidades pode dessensibilizar e destruir a emoção humana e, portanto, a própria humanidade (ODELL; LE BLANC, 2009, 195-196, tradução nossa).
\end{abstract}

Um elemento chave para compreender a animação é o fato de que o principal protagonista, Seita, não é um herói no sentido tradicional, mas uma vítima que tenta desesperadamente sobreviver junto com sua irmã. Ele é imaturo, orgulhoso, teimoso, reacionário e irresponsável. Um personagem no qual podemos identificar muitas emoções humanas e cujos erros, proporcionados por suas ações e inações, culminaram numa morte patética e anônima, destacada na abertura do próprio filme (ODELL; LE BLANC, 2009).

A interpretação acerca do título da animação pode servir tanto como um dispositivo temático quanto metafórico, pois há uma relação entre os vagalumes e os aviões bombardeiros. O vislumbre fugaz da felicidade é proporcionado pela luminosidade dos vagalumes que, ao serem acidentalmente esmagados pelas mãos de Setsuko, involuntariamente ensinam a preciosa lição sobre a brevidade da vida. Já o vislumbre dos aeroplanos cujo brilho só se diferencia daquele dos insetos em termos de proporção e distância. Os aviões são como os vagalumes no céu. De longe não dá para saber se os pontos brilhantes no céu são os insetos ou se são fogos dos bombardeios. Em todos esses casos, temos a representação da brevidade da vida: a dos vagalumes, que perecem duas semanas após brilharem; a das pessoas cujo derradeiro vislumbre é o das

Doutor em Filosofia (UFSCAR). Docente do Programa de Pós-graduação em Filosofia (UFPI). Brasileiro. Residente em Teresina-PI. E-mail: heraldokf@yahoo.com.br

Graduanda em Pedagogia. Bolsista de Iniciação Científica PIBIC/CNPq (UFPI). Brasileira. Residente em Teresina-PI. E-mail: laralima18@hotmail.com 
bombas caindo dos aviões e, finalmente, a dos protagonistas, Seita e Setsuko que, desde o início, também estavam precocemente destinados ao túmulo (ODELL; LE BLANC, 2009).

\section{Narrativa}

O filósofo ensaísta e crítico literário Walter Benjamin, de origem alemã viveu entre os séculos $\mathrm{XIX}$ e $\mathrm{XX}$, durante o período conturbado da $2^{\circ}$ guerra Mundial com a ascensão do nazismo na Alemanha. Sofreu forte influências do romantismo alemão, marxismo e da religião judaica da qual fazia parte. Estudou filosofia; literatura alemã e história da arte. Escreveu sobre um leque amplo de temas destacando-se os temas referentes à literatura, arte e estrutura social. Considerado um pensador influente, distinguiu-se de outros pensadores pela sua forma de trabalhar a história em uma perspectiva dialética e revolucionária. Responsável pela produção de variados artigos e ensaios.

Benjamin dá início ao seu ensaio, $O$ narrador: Considerações sobre a obra de Nikolai Leskov, tecendo considerações sobre a arte de narrar e o possível fim que está levando a narrativa, e os principais fatores que levam ao seu desaparecimento, dentre ele pode-se citar o surgimento do romantismo com a proposta de um sujeito individual e isolado, posteriormente com a explosão da informação foi-se perdendo a essência da narrativa que culminou na pobreza de experiência presente na modernidade, em que os indivíduos se encontram carentes de novas experiências. Por conseguinte, a arte de narrar não se destina a qualquer pessoa, pois somente o narrador pode absorver e repassar sua narrativa deixando nela sua marca de experiência. E para ele entre as narrativas escritas as melhores são as que menos se distinguem das histórias orais, passadas de pessoa para pessoa e que permitem a conservação da tradição (BENJAMIN, 1994b).

Ele classifica o narrador em duas categorias: os que viajam e vem de longe, que ganha sua vida realizando viagens e vivenciando de novas experiências, para exemplificar ele utiliza a figura do marinheiro comerciante, e aqueles que nunca ousaram sair do país, mas vivenciaram as tradições de sua terra, esse é representado pelo camponês sedentário. Esses dois tipos de 
narradores foram responsáveis pela conservação da narrativa, que possibilitou a evolução e reprodução das tradições por meio da arte de contar história (BENJAMIN, 1994b).

O narrador benjaminiano é comparado a um artesão e a narrativa à sua obra prima. O trabalho manual do artesão consiste na produção de determinado objeto ou artefato, realizado tão somente pelas suas experiências. Desta forma o narrador é aquele que produz sua narrativa e deixa nela sua marca. "[...] Assim se imprime na narrativa a marca do narrador, como a mão do oleiro na argila do vaso" (BENJAMIN, 1994b, p. 205) A narrativa torna se então o elo entre o narrador e o ouvinte, é por meio da história que a tradição acontece. O narrador torna-se o produtor de sua narrativa, e terá o ofício de mantê-la e repassa lá para que a tradição de narração de história não venha se perder.

\begin{abstract}
O senso prático é uma das características de muitos narradores natos... A natureza da verdadeira narrativa. Ela tem sempre em si, as vezes de forma latente, uma dimensão utilitária. Essa utilidade pode consistir seja num ensinamento moral, seja numa sugestão prática, seja num provérbio ou numa normal de vida de qualquer maneira 0 narrador o narrador é um homem que sabe dá conselhos. (BENJAMIN, 1994b, 203).
\end{abstract}

Uma característica relevante da narrativa é o seu senso prático, carregada de um valor ético, dela pode-se retirar a moral da história, que tem a função de provocar uma reflexão proporcionar um ensinamento. Essa característica revelaria então o narrador como um conselheiro, e o Conselho retirado de dentro da narrativa seria o que Benjamin chama de sabedoria, a arte de narrar seria o lado épico da verdade, nem todos saberiam receber conselhos, assim como poucos saberão narrar. Por isso, também é necessário que aquele que ouve possa juntamente com o narrador manter o interesse em conservar o que foi narrado: "[...] A experiência que passa de pessoa a pessoa é a fonte que recorrem todos os narradores, e entre as narrativas escritas, as melhores são as que menos se distingue das histórias orais..." (BENJAMIN,1994b, 198).

Desse modo, as histórias contadas de pessoa para pessoa mantiveram a tradição viva, e elas não se diferenciam das histórias escrita, pelo contrário tendem a aproxima-se. O elo que as mantêm que é de crucial importância é a memória, a musa épica da narrativa, é ela que mantêm o vínculo entre as

Doutor em Filosofia (UFSCAR). Docente do Programa de Pós-graduação em Filosofia (UFPI). Brasileiro. Residente em Teresina-PI. E-mail: heraldokf@yahoo.com.br

Graduanda em Pedagogia. Bolsista de Iniciação Científica PIBIC/CNPq (UFPI). Brasileira. Residente em Teresina-PI. E-mail: laralima18@hotmail.com 
gerações. A memória é vista como a evocação do passado, a tentativa de recordar de fatos e acontecimentos vividos, a substância da sua identidade, está imbricada na arte de narrar de repassar as gerações.

Walter Benjamin aponta Nikolai Leskov, como o exemplo de um narrador nato, e é nele que se encontram tais características. Porém ao invés de se aproximar parece que esse narrador mantêm uma distância cada vez maior entre nós. Em seu ensaio ele enfatiza a contradição existente entre tradição e modernidade. O lapso causado entre ambos, a morte da narrativa e a pobreza de experiência. E salienta para a importância da narrativa como a fonte da experiência que não pode tão cedo chegar a um fim trágico. O papel imprescindível do narrador como o mediador entre a história e o ouvinte. A tradição da contação de história que aproximou os homens, o compartilhamento de experiência que fazem do narrador estar entre sábios e mestres, pois só ele é capaz de repassar a realidade por meio da narrativa, de forma que ela se torne útil para quem ouviu e que possa ser repassada adiante como um património que assegure a tradição, a preservação da cultura enraizada no povo.

\section{Experiência}

A narrativa encontra-se na ação da experiência. Conforme Larrosa (2002), experiência é o que nos passa, o que nos acontece, o que nos toca. $A$ experiência consiste então na ação direta que afeta o sujeito, ou seja, a experiência torna-se algo subjetivo a cada indivíduo. Ao mesmo tempo que a experiência é algo particular ela poderá ser apropriada por outros e acabar convertendo-se em uma nova experiência.

\footnotetext{
Por isso, o saber da experiência é um saber particular, subjetivo, relativo, contingente, pessoal. [...] O saber da experiência é um saber que não pode separar-se do indivíduo concreto em quem encarna. Não está, como o conhecimento científico, fora de nós, mas somente tem sentido no modo como configura uma personalidade, um caráter, uma sensibilidade ou, em definitivo, uma forma humana singular de estar no mundo, que é por sua vez uma ética (um modo de conduzir-se) e uma estética (um estilo). Por isso, [...] ninguém pode aprender da experiência de outro, a menos que essa experiência seja de algum modo revivida e tornada própria (LARROSA, 2002, 27).
}

Doutor em Filosofia (UFSCAR). Docente do Programa de Pós-graduação em Filosofia (UFPI). Brasileiro. Residente em Teresina-PI. E-mail: heraldokf@yahoo.com.br

Graduanda em Pedagogia. Bolsista de Iniciação Científica PIBIC/CNPq (UFPI). Brasileira. Residente em Teresina-PI. E-mail: laralima18@hotmail.com 
A experiência é vista aqui com o viés filosófico, carregado do sentimento, da vivência e do cotidiano. Ela se distingui então de uma visão técnica que a reduz ao mero experimento, isolado. Porém Benjamin é enfático quando se refere ao sentimento que provoca no indivíduo algum resultado e, é essa experiência que o narrador vive. A narrativa só acontece por que alguém foi capaz de sentir, de ser tocado e pode repassar isso transformando-a em um saber, que terá a finalidade de ser útil a alguém. É nessa contradição da tradição versus a modernidade que se percebe que a simples ação da experiência está se esvaziando a cada dia, pois o que era responsável pela conservação da tradição perdeu seu valor na modernidade (BENJAMIN, 1994a).

Larrosa (2002) aponta para os motivos que ocasionaram na pobreza de experiência, e consequentemente no empobrecimento das relações humanas. A falta de experiência encontra-se no excesso de informação, surge então a urgência de informar e estar informado. "A informação só é relevante quando nova" (BENJAMIN, 1994b). O imediatismo requer coisas prontas e rápidas e não há tempo para viver coisas novas. Está no excesso de opinião, onde o mais importante que é o conhecimento, tem sido trocado por meros achismos e opiniões rasas sem nenhum embasamento. Está também no excesso de trabalho, onde o homem não mais trabalha para viver e sim, vive para trabalhar; resume-se a um sujeito isolado resultado de um sistema controlador e explorador. E por fim tudo isso resultará na falta de tempo, um dos maiores inimigos da experiência esse é o resultado de um paradoxo sem fim, que necessita de equilíbrio entre o excesso e a falta. Ele tem tornado os indivíduos distantes e provocado o silêncio (BENJAMIN, 1994a).

Conforme Benjamin, em seu ensaio Experiência e Pobreza: a ação da experiência está em baixa, e as experiências vivenciadas pelas gerações que viveram a $1^{\text {a }}$ Guerra Mundial, foram silenciados pela dor e pela tragédia.

Não, está claro que as ações da experiência estão em baixa, e isso
numa geração que entre 1914 e 1918 viveu uma das mais terríveis
experiências da história. [...] Na época já se podia notar que os
combatentes tinham voltado silenciosos do campo de batalha. Mais
pobres em experiências comunicáveis, e não mais ricos. [...] Porque
nunca houve experiências mais radicalmente desmoralizadas que a
experiência estratégica pela guerra de trincheiras, a experiência

Doutor em Filosofia (UFSCAR). Docente do Programa de Pós-graduação em Filosofia (UFPI). Brasileiro. Residente em Teresina-PI. E-mail: heraldokf@yahoo.com.br

Graduanda em Pedagogia. Bolsista de Iniciação Científica PIBIC/CNPq (UFPI). Brasileira. Residente em Teresina-PI. E-mail: laralima18@hotmail.com 
econômica pela inflação, a experiência do corpo pela fome, a experiência moral pelos governantes (BENJAMIN, 1994a, 114-115).

O silêncio impede que as experiências sejam externadas e muito menos vivida. Junto a modernidade sobrevieram muitas coisas, assim também como muitas coisas foram se perdendo. Surge então o desejo de se libertar das experiências passadas para se viver a contingência do futuro. $O$ filósofo alemão alerta para que a ação da experiência não possa se esvaziar, nem perder 0 sentido, pelo quão importantes elas são e representam para a humanidade. $O$ verdadeiro tesouro escondido nos vinhedos (BENJAMIN, 1994a).

\section{Túmulo dos Vagalumes e Walter Benjamin}

Benjamin (1994a) aponta para o empobrecimento das experiências causado pela guerra que provocou um emudecimento em a quem vivenciou. $\mathrm{E}$ posteriormente o que se teve foram apenas tentativas de se retratar de forma alheia retratos de uma guerra. Nessa perspectiva, Túmulo dos Vagalumes é uma animação cinematográfica adaptada de um conto que possui traços de uma experiência pessoal semibiográfica ambientada no cenário de guerra, fazendo o espectador voltar no tempo e vivenciar uma experiência que poucos se atrevem a viver.

Os personagens protagonistas retratados no drama encaram a vida sob perspectivas diferentes. O irmão mais velho Seita, caracteriza-se por ser um personagem responsável, desde tão jovem recai sobre si a responsabilidade de cuidar de sua irmã, e para isso ele é capaz de enfrentar qualquer situação para protegê-la. Um personagem de personalidade altiva, que representa a força e coragem do povo japonês diante das dificuldades. Já Setsuko a irmã pequena e inocente, vivencia em sua pouca idade as tragédias e conflitos de uma guerra, no entanto por sua forma pueril de ver o mundo, ela não tem a percepção do mal a sua volta; ela exprime as típicas vítimas fatais da guerra, que são os principais afetados. O que esses personagens possuem em comum é o fato de compartilharem características do narrador benjaminiano.

O narrador de Túmulo dos vagalumes apresenta em suas dimensões aspectos do narrador de Benjamin (1994b), porque ele mantém um vínculo Doutor em Filosofia (UFSCAR). Docente do Programa de Pós-graduação em Filosofia (UFPI). Brasileiro. Residente em Teresina-PI. E-mail: heraldokf@yahoo.com.br

Graduanda em Pedagogia. Bolsista de Iniciação Científica PIBIC/CNPq (UFPI). Brasileira. Residente em Teresina-PI. E-mail: laralima18@hotmail.com 
íntimo com os elementos da narrativa, ou seja, a experiência relatada não é um fato alheio ao personagem, pois ele mesmo a vivenciou, e ao narrar sua experiência, esse narrador incorpora coisas narradas à experiência de seu ouvinte. A animação inicia com uma marca não muito comum, ela começa apresentado o final da história. O narrador inicia sua fala com o ano de sua morte, e a partir desse momento a história vai ganhando um contorno, o narrador relata sua vida enquanto de longe a observa. Esse narrador se assemelha ao clássico narrador que Benjamin classifica como aquele que nunca saiu de sua terra. De fato Seita nunca saiu do Japão, mas com seu olhos poder ver as mudanças repentinas de um Japão que viveu da tradição para a modernidade, da prosperidade para a terrível guerra, e foi nesse cenário que viveu uma das experiências mais desanimadoras de sua vida.

As experiências vivenciadas pelos dois irmãos na animação são suficientes para representar o que muitos outros viveram ou sofreram nesse referido período. $\mathrm{O}$ empobrecimento das relações já se mostrava acentuados. Isso é demostrado nitidamente em Túmulo dos vagalumes, onde cada personagem é capaz de se transformar drasticamente em pouco tempo, nesse período conturbado de extremos, onde os sentimentos humanos se esvaziam e a sociedade perde sua humanidade. E quando as pessoas perdem a sua voz, isto é, a sua capacidade de narrar para outros a sua experiência pessoal, elas também perdem a sua individualidade (BENJAMIN, 1994a; 1994b).

Outra dimensão presente na animação é o senso prático que a narrativa possui, que provoca um efeito moralizante, que se torna útil. Neste caso Túmulo dos vagalumes é uma história que carrega em si uma genial mensagem que visa alcançar o espectador provocando uma reflexão não somente acerca da guerra, mas também com relação aos pequenos detalhes presentes em uma cena, ou em um objeto. Por exemplo; em determinada cena Seita encontra soterrado nos escombros de sua casa uma latinha de balas de frutas, e a dá de presente para sua pequena irmã, esse objeto torna os motivos de alegria e doçura da pequena. Esse pequeno objeto além de representar os momentos felizes entre os irmãos, também simboliza a eternização de momentos que os dois gostariam de guardar, em suas memórias como algo de bom, e no final essa foi a única coisa que restou 
dos dois irmãos. O enredo, os personagens e a história aplicam uma lição de moral sobre muitos aspectos, desde as consequências da guerra, a indiferença do Homem, a sutileza nas pequenas coisas com o propósito de demonstrar a realidade.

\begin{abstract}
Assim definido, o narrador figura entre os mestres e os sábios. Ele sabe dar conselhos: não para alguns casos, como os sábios Provérbios, mas para muitos casos como o sábio. Pois pode recorrer ao acervo de toda uma vida (uma vida que não inclui apenas a própria experiência, mas em grande parte a experiência alheia. $O$ narrador assimila à sua substância mais íntima aquilo que sabe por ouvir dizer). Seu dom é poder contar sua vida; sua dignidade é contá-la inteira. (BENJAMIN, 1994b, 221).
\end{abstract}

Se o dom do narrador é contar sua história, mas também compartilhar de experiência de outrem, então porque não dizer que Isao Takahata figura entre mestre e o sábio. As razões para tal afirmações se encontram Primeiro, pelo fato de sua obra prima transcender o tempo e o espaço, ele te leva até o passado, em um Japão de 1945, e mostra a veracidade de uma história, sem precisar máscara ou romantizar os fatos para agradar determinado público. No entanto seu único interesse foi repassar a verdade de uma história que originalmente não é sua, mas que teve um impacto em sua vida, pois ele mesmo viveu de tais experiências, quando passou junto com sua família os horrores da $2^{\circ}$ guerra Mundial.

Ele se configura como um sábio ou um mestre porque por intermédio de sua obra proporcionou ao mundo uma experiência única de historicidade e empatia, deixando a importante reflexão acerca dos relacionamentos humanos, das tragédias provocadas pela guerra. Ele finaliza sua obra com a imagem dos dois irmãos anos depois, à observarem a cidade reconstruída e moderna com seus altos edifícios e prédios, ali naquele mesmo lugar eles vivenciaram uma experiência terrível, que talvez as futuras gerações que ali viviam nunca poderiam entender, todavia seus espíritos jaziam ali silenciadas a contemplar um nova era, mas sem se esquecerem do passado, afinal suas vidas jamais serão esquecidas enquanto forem narradas para as próximas gerações.

Doutor em Filosofia (UFSCAR). Docente do Programa de Pós-graduação em Filosofia (UFPI). Brasileiro. Residente em Teresina-PI. E-mail: heraldokf@yahoo.com.br

Graduanda em Pedagogia. Bolsista de Iniciação Científica PIBIC/CNPq (UFPI). Brasileira. Residente em Teresina-PI. E-mail: laralima18@hotmail.com 


\section{CONCLUSÃO}

Walter Benjamin situa-se no campo da literatura, artes e filosofia, a União de seus pensamentos contribui para uma reflexão crítica. Suas observações críticas ao que concerne o empobrecimento das relações humanas, a falta das trocas de experiências que foram fatores decisivos na morte da narrativa, tornam-se tão recentes, e se acentuam ainda mais em nossos dias.

A narrativa perdeu seu espaço para o romance e para a informação, já não há mais tempo para se viver uma nova experiência, e a tradição não possui uma validade no mundo moderno e rápido, em que as coisas possuem um valor efêmero, marcado por uma geração que pouco lhes interessa parar, nem que seja por um minuto para, sentir, refletir e viver. A narrativa então demonstra ser contrário do que vemos hoje, pois ela produz no indivíduo o prazer da experiência, da tradição do saber, por esta razão Benjamin exalta o narrador, este ser que consegue absorver o saber da narrativa

Túmulo dos vagalumes compartilha uma relação com os escritos de Walter Benjamin, e isso porque a narrativa e o narrador abordado por Benjamin estão presentes no enredo de Isao Takahata, quando ele retrata em sua obra Seita e Setsuko. Esses dois personagens que por sua história de vida compartilharam ao público não somente uma simples história, mas uma verdadeira lição de vida, para aqueles que com sensibilidade conseguiram captar a mensagem narrada. Assim também como o próprio roteirista situa-se dentro desta relação a obra e autor, como a narrativa e o narrador, uma experiência compartilhada que é capaz de proporcionar em seus espectadores novas experiências.

\section{REFERÊNCIAS}

BENJAMIN, Walter. Experiência e pobreza. In_ : Magia e técnica, arte e política: ensaios sobre literatura e história da cultura. $7^{\text {a }}$ ed. Trad. Paulo Sérgio Rouanet. São Paulo, Brasiliense, 1994a. p. 114-119.

BENJAMIN, Walter. O narrador: Considerações sobre a obra de Nikolai Leskov. In _ : Magia e técnica, arte e política: ensaios sobre literatura e história da Doutor em Filosofia (UFSCAR). Docente do Programa de Pós-graduação em Filosofia (UFPI). Brasileiro. Residente em Teresina-PI. E-mail: heraldokf@yahoo.com.br

Graduanda em Pedagogia. Bolsista de Iniciação Científica PIBIC/CNPq (UFPI). Brasileira. Residente em Teresina-PI. E-mail: laralima18@hotmail.com 
cultura. Trad. Sérgio Paulo Rouanet. São Paulo, Brasiliense, 1994b. p. 197221.

ISAO TAKAHATA (1935-2018). In_ : Internet Movie Database - IMDB, 2018. Disponível em: <https://m.imdb.com/name/nm0847223/?ref_=fn_al_nm_0 $>$. Acesso em: 15 ago. 2019.

LARROSA, Jorge. Notas sobre a experiência e o saber de experiência, In Revista Brasileira de Educação, n.19, Campinas, 2002, p. 20-28.

MOLINÉ, Alfons. O grande livro dos mangás. São Paulo: JBC, 2006.

ODELL, Colin; LE BLANC, Michelle. Studio Ghibli: The Films of Hayao Miyazaki and Isao Takahata. Harpenden, UK: Kamera Books, 2009.

O TÚMULO DOS VAGALUMES - Hotaru no Haka (1988). In_ : YouTube. 2016. Disponível em: < https://www.youtube.com/watch?v=luabb7q1M8c>. Acesso em: 22 ago. 2019.

STUDIO GHIBLI. Studio Ghibli Brasil. (2004). Disponível em: <https://studioghibli.com.br/studioghibli/>. Acesso em:14 ago. 2019. 